\title{
KOLOKASI BERKONTRUKSI "NOMINA + VERBA" DALAM \\ BAHASA JEPANG PADA MINNA NO NIHONGO SHOKYUU \\ DAN NIHONGO CHUUKYUU
}

\author{
Amalia Rizqi Khoiriyah \\ Fakultas Bisnis dan Bahasa Unipdu, amaliarizqik@gmail.com
}

\begin{abstract}
This research is motivated by the existence of problems in language, because each language has their own habits to join the words with certain words. This habit is called collocation. The focuss in this study, is the use of collocation with the construction of "Nomina + Verba" and its role in Japanese in Minna no Nihongo Shokyuu and Nihongo Chuиkyuu. Collocation with verb types is considered as the focus in this study, because verbs are 'lives' in a sentence. The results of this study indicate that the construction of nouns + verbs on Nihongo Shokyuu and Nihongo Chuukyuu are 4 constructions: (a) Noun + wo + Verba there are 3 roles of syntax, namely Objective, Locative and role of Time, (b) Noun $+\mathrm{ni}+$ Verb role found are Objective, Locative, Time, Opposition, Direction, Giver, Receiver and Results role roles, c) Noun + ga + role verbs which are objectivepatient roles. This is because the construction that meets Nomina + Verba requirements is only in the patient role. Then the last one is construction (d) Nominal + de + Verba with 4 synthetic roles, Locative's role, Time, Instrument and cause / reason. The type of collocation studied is limited collocation, fixed collocation and idiom.
\end{abstract}

Keywords: collocation, syntatic role and type of collocation

\section{PENDAHULUAN}

Kesulitan berbahasa dan kesalahan dalam berbahasa timbul karena setiap bahasa mempunyai kebiasan masing-masing untuk menggabungkan suatu kata dengan kata tertentu. Hal ini sering menimbulkan kebingungan karena terkadang ada hubungan yang tidak logis antara kata apa yang bergabung dengan kata apa. Fenomena kebahasaan semacam ini dalam linguistik dikenal dengan istilah kolokasi.

Kridalaksana (2009:127) menjelaskan bahwa kolokasi adalah asosiasi yang tetap antara kata dengan kata lain yang berdampingan dalam kalimat. Sebagai contoh, adalah kata buku dan tebal dalam kalimat Buku tebal ini mahal. Jadi, kolokasi adalah kecenderungan sejumlah kata untuk bergabung secara teratur dalam suatu bahasa. Kolokasi sangat penting untuk memperoleh kelancaran dan 
kealamian dalam berbahasa, karena kolokasi dapat menafsirkan keseluruhan makna dari elemen penyusun individu dan terkadang juga sulit untuk menentukan suatu pasangan kata karena pasangan kata yang menurut pembelajar aneh dan tidak berterima. Pembelajar yang tidak sadar akan kolokasi tidak mungkin melakukan pembelajaran kolokasi dengan menggunakan alat penelusuran di Internet dan materi pengajaran tambahan tentang kolokasi. Kerumitan tersebut dapat diselesaikan dengan mengajarkan kosakata kepada pembelajar dengan cara mengajarkan pula kolokasinya. Salah satu metode yang efektif adalah dengan mengajarkannya secara terpadu kepada pembelajar.

\section{PEMBAHASAN}

Dalam penelitian ini ditemukan sebanyak 459 data kalimat yang mengandung pola kolokasi dengan konstruksi nomina +verba.. Berikut temuan pola kolokasi dengan konstruksi nomina +verba dalam bahasa Jepang pada buku Minna no Nihongo I, II dan Nihongo Chuukyuu I, II yang disajikan dalam bentuk tabel.

Tabel 1 Pola Kolokasi dengan konstruksi Nomina + Verba dalam Minna no Nihongo Shokyuu I, II dan Nihongo Chuukyuu I, II

\begin{tabular}{|l|l|l|}
\hline No & $\begin{array}{l}\text { Kolokasi dengan } \\
\text { Konstruksi Nomina }+ \\
\text { Verba }\end{array}$ & Jumlah \\
\hline 1. & Nomina $+o+$ Verba & 164 \\
\hline 2. & Nomina $+n i+$ Verba & 123 \\
\hline 3. & Nomina $+g a+$ Verba & 150 \\
\hline 4. & Nomina $+d e+$ Verba & 22 \\
\hline \multicolumn{2}{|l|}{ Total Data } & 459 data \\
\hline
\end{tabular}

Dari tabel di atas, dapat disimpulkan bahwa kolokasi dengan konstruksi Nomina $+w o+$ Verba adalah konstruksi dengan jumlah kolokasi terbanyak. 
Sedangkan pada konstruksi Nomina $+d e+$ Verba merupakan data terendah ditemukannya kolokasi.

\section{Konstruksi Nomina $+o+$ Verba}

Konstruksi yang pertama adalah Konstruksi Nomina $+o+$ Verba. Pada pola konstruksi ini, data yang didapat sejumlah 164 data. Partikel $o$ termasuk dalam kakujoshi. Kakujoshi atau biasa disebut dengan partikel kasus, merupakan kategori gramatikal dari nomina, frasa nominal dan pronomina yang memperlihatkan hubungannya dengan kata lain dalam konstruksi sintaksis. Peran dari partikel $o$ pada pola konstruksi ini ada empat (4), yakni:

\subsection{Pasien/Objektif (対象)}

Peran pertama pada pola konstruksi Nomina $+o+$ Verba adalah peran pasien/objektif. Berikut beberapa data mengenai partikel $o$ yang menunjukkan peran pasien/objektif $o$ dalam konstruksi Nomina $+o+$ Verba dalam kalimat bahasa Jepang: Pada data (1) doa 'pintu' merupakan nomina yang mendapat pengaruh akibat suatu perbuatan. Unsur yang mendapat pengaruh adalah pintu sebagai nomina dan perbuatan yang menyebabkan terjadinya sesuatu diungkapkan dengan verba membuka. Peran partikel o pada kalimat doa o akemasu (membuka pintu) menunjukkan adanya valensi hubungan dari verba kepada nomina yang dapat disebut dengan peran objektif.

Data (2) verba yarimasu (memberi) memberi dampak pada pasien yakni nomina esa (makananan). Kata yarimasu biasa digunakan untuk menunjukkan verba yang berhubungan dengan hewan. Hal ini didasari oleh kebiasaan orang Jepang ketika menggunakan bahasa, melihat sudut pandang tentang hierarki insani, bahwasanya manusia lebih tinggi derajatnya dibandingkan dengan binatang.

(1) ドア を 閉めます

Doa o Akemasu

Pintu Obj Membuka

(Saya) membuka pintu 
(2) 犬にえさを やります Inu ni esa o Yarimasu

Anjing LB makanan Obj Memberi

(Saya) Memberi makanan kepada Anjing

(131/16/MNSI)

Peran sintaksis pada partikel $o$ pada data di (1) dan (2) menunjukkan peran pasien pada nomina. Hal ini sesuai dengan yang disampaikan Verhaar (2010:175) bahwa salah satu peran dari sintatik adalah sebagai pasien. Nomina pada kasus ini ditandai oleh nomina yang berupa orang, binatang, benda atau sesuatu yang sebanding. Jenis kolokasi pada data (1) adalah kolokasi terbatas, sedangkan pada data (2) termasuk dalam jenis terikat.

\subsection{Lokatif (Tempat)}

Pada kakujoshi $o$, peran lokatif (tempat) dibagi menjadi dua peran, yaitu tempat keluar dan tempat melewati.

(3) 会社 を やめます

Kaisha O Yamemasu

Perusahaan Lok Berhenti

(Saya) Berhenti (dari) perusahaan

(4/26/MNS II)

Pada data (3) kakujoshi o yang melekat pada nomina kaisha (perusahaan) sebagai tempat yang pernah ditempati bekerja oleh subjek yang dilesapkan atau pada data ini, subjek Saya tidak dimunculkan. Verba yamemasu (berhenti) yang bervalensi pada nomina kaisha (perusahaan), merupakan verba yang aktif. Artinya, verba ini menuntut adanya aktifitas yang mendasari adanya proses berhenti tersebut. Jadi, dapat disimpulkan bahwasanya peran partikel $o$ pada kalimat Berhenti dari perusahaan yang melekat pada nomina perusahaan menunjukkan tempat keluarnya Subjek dari suatu tempat. Hal ini sesuai dengan 
peran partikel $o$ yang menunjukkan lokasi, atau dalam hal ini tempat keluarnya sesuatu. Jenis kolokasinya adalah kolokasi terbatas.

$$
\begin{array}{ll}
\text { 公園 を } & \text { さんぽします } \\
\text { Kouen O } & \text { Sanposhimasu } \\
\text { Taman Lok } & \text { berjalan-jalan } \\
\text { Berjalan-jalan di taman }
\end{array}
$$

\section{(46/31/MNS II)}

Begitu pula dengan data (4), pada data ini Nomina yang dimunculkan adalah nomina yang menunjukkan lokasi atau tempat. Kouen (taman) adalah nomina yang menunjukkan tempat pada aktifitas sanposhimasu (berjalan-jalan). Partikel $o$ yang melekat pada nomina menunjukkan peran lokasi atau tempat pada nomina kouen. Verba sanposhimasu menunjukkan adanya implikasi bahwa Subjek tidak hanya berjalan pada satu tempat saja, tapi ada pergerakan alih dari satu tempat ke tempat lain, berbeda halnya dengan verba aruku (berjalan) yang hanya berfokus pada satu tempat saja. Dari sini dapat ditarik kesimpulan, bahwa verba yang harus muncul pada peran lokasional tempat melewati harus verba yang berjenis idou doushi (gerak alih). Kolokasi pada data (4) termasuk dalam kolokasi terbatas.

\subsection{Waktu（経過する時間）}

Peran partikel $o$ sebagai partikel yang melekat pada nomina selanjutnya adalah peran yang menunjukkan waktu. Berikut contoh datanya.

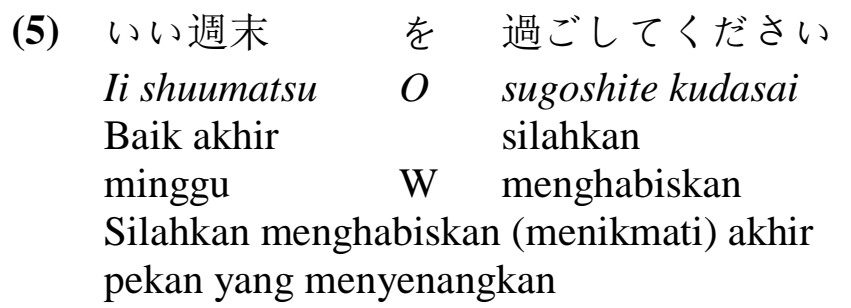

(198/49/MNS II) 
Peran partikel $o$ sebagai waktu yang telah dilewati lebih terlihat jelas pada data (5). Pada kalimat 'Silahkan menghabiskan akhir pekan yang menyenangkan', konstruksi yang digunakan adalah konstruksi Nomina $+o+$ Verba. Nomina shuumatsu artinya adalah akhir minggu. Nomina ini menunjukkan waktu kejadian. Partikel yang melekat pada nomina ini berperan sebagai waktu yang telah lewat. Verba yang bervalensi pada nomina shuumatsu adalah verba shugosu yang dalam bahasa Indonesia adalah menghabiskan. Dalam kegiatan menghabiskan akhir pekan, ada rentang waktu yang dilewati. Karena akhir pekan biasanya terdiri dari dua hari yakni hari Sabtu dan Minggu. Pada rentang waktu ini, biasanya dihabiskan dengan kegiatan bersenang-senang bersama keluarga ataupun beristirahat di rumah. Adanya aktifitas selama rentang waktu inilah yang mendasari peran waktu yang dilewati pada partikel wo yang melekat pada nomina shuumatsu. Kolokasi ini termasuk kolokasi terbatas.

\subsection{Menjauhi objek (離れる対象)}

Peran keempat dari partikel $o$ pada konstruksi Nomina $+o+$ Verba adalah menjauhi objek. Berikut beberapa data yang berhasil ditemukan pada penelitian ini:

(6) バス を 降ります

Basu o Orimasu

Bus JO Turun

Turun (dari) bus (72/34/MNS II)

(7) たばこ を やめます

Tabako o Yamemasu

Rokok JO Berhenti

Berhenti merokok

(48/6/NGC I)

Begitu pula dengan data (6) dan data (7). Pada kedua data ini, verba yang digunakan adalah verba oriru (turun) dan yameru (berhenti). Pada data (6) verba 
oriru menunjukkan aktifitas menjauh dari nomina basu, dan verba yameru pada data (7) mengindikasikan adanya kegiatan behenti menjauhi rokok. Kedua data ini berjenis kolokasi terbatas.

\section{Konstruksi Nomina $+n i+$ Verba}

Peran dari partikel $n i$ pada pola konstruksi ini ada 8 (delapan) peran penanda kasus, yakni:

\subsection{Objektif-Pasien（対象）}

Peran pertama dari partikel $n i$ pada konstruksi Nomina $+n i+$ Verba adalah sebagai pasien. Berikut beberapa data yang berhasil ditemukan pada penelitian ini:
(8)このいす に かけてください
Kono isu Ni kaketekudasai
Kursi ini Obj silahkan duduk
Silahkan duduk di kursi ini

$(192 / 23 /$ MNS I)

Peran pertama dari partikel $n i$ pada data (8) dan data (9) adalah sebagai objektif. Pada data (8), peran objektif ditunjukkan oleh nomina isu yang dalam bahasa Indonesia berarti kursi. Kursi berperan sebagai pasien karena kursi merupakan objek yang mendapat pengaruh dari verba kakeru. Kakeru dalam bahasa KBBJI berarti mengenakan, melakukaan, dan meletakkan. Pada data (8) pengertian dari kakeru adalah meletakkan. Subjek yang tidak disebutkan pada data, meletakkan bagian tubuhnya ke kursi, implikasi ini mengindikasikan adanya kegiatan duduk. Karena dalam kegiatan duduk, biasanya yang diletakkan adalah tubuh bagian bagian ke suatu benda (kursi). Hal ini sesuai dengan peran partikel $n i$ yang berperan sebagai objektif. Jenis kolokasinya adalah kolokasi idiom.

\subsection{Lawan（相手）}

Peran partikel $n i$ yang melekat pada konstruksi nomina $+n i+$ verba berikutnya adalah sebagai penanda lawan bicara. Berikut contoh datanya:

(9)

$\begin{array}{lll}\text { 係員 } & \text { に } & \text { 連絡しますから } \\ \text { Kakariin } & n i & \text { renrakushimasu kara, }\end{array}$

http://journal.unesa.ac.id/index.php/paramasastra |130 


\author{
Staf LB karena menghubungi \\ Karena telah menghubungi staf \\ (171/46/MNS II) \\ (10) 先生の奥様 に おめにかかりました \\ Sensei no \\ okusama ni ome ni kakarimashita \\ Guru JD \\ istri LB mata JD mengambil \\ Bertemu dengan Istri pak guru \\ (204/50/MNS II)
(11) 中村にお会いになれなかった
Nakamura ni o ai ni narenakatta
Nakamura LB Berjumpa
Tidak bisa berjumpa dengan Nakamura

(33/4/NGC I)

Pada data (9) berkonstruksi Nomina+ni+Verba. Verba renrakushimashita 'menghubungi' dan merupakan verba aktif yang mengindikasikan adanya komunikasi antara penutur dengan lawan bicara. Lawan bicara pada kalimat ini ditunjukkan denga nomina kakariin 'staf'. Partikel ni yang melekat pada nomina menunjukkan peran nomina sebagai lawan bicara dari penutur. Kolokasi ini masuk dalam jenis kolokasi terbatas.

Pada data (10) dan (11) ome ni kakaru dan oaininarenakatta termasuk dalam frasa yang dapat diartikan bertemu. Frasa ini tidak dapat dipisahkan ataupun diartikan secara satu per satu per kata. Karena apabila diartikan satu persatu akan terjadi kerancuan dan ketidakberterimaan dalam bahasa. Omenikakaru berarti bertemu atau menyapa, sedangkan oaininarenakatta adalah berjumpa. Pada data (10) nomina yang mengikuti frasa ini adalah sensei no okusama yang artinya dalam bahasa Indonesia adalah Istri guru dan pada data (11) adalah Nakamura. Partikel $n i$ pada kedua data ini mengindikasikan bahwa nomina berperan sebagai lawan. Lawan pada data ini adalah lawan bertemu, dan tidak ada

131 | http://journal.unesa.ac.id/index.php/paramasastra 
komunikasi aktif, hanya kegiatan bertemu saja. Jenis kolokasi pada kedua data ini adalah kolokasi idiom.

Ketiga data tersebut, menunjukkan bahwa lawan, bukan berarti lawan bicara saja, tapi juga bisa menunjukkan peran lawan bertemu atau lawan pasangan dalam suatu kegiatan.

\subsection{Lokatif (Tempat) （ところ）}

\section{a. Tempat sesuatu berada（存在するところ）}

Peran ketiga pada partikel $n i$ adalah sebagai partikel yang melekat pada nomina yang menunjukkan tempat sesuatu berada. Berikut contoh datanya:

\begin{tabular}{|c|c|c|c|}
\hline \multirow[t]{3}{*}{ (12) } & ホテル & に & 泊まる \\
\hline & Hoteru & $N i$ & tomaru \\
\hline & Hotel & $\mathrm{TB}$ & menginap \\
\hline & \multicolumn{3}{|c|}{ Menginap di hotel } \\
\hline & & & (44/5/NGC II) \\
\hline \multirow[t]{4}{*}{ (13) } & 大使館 & に & 勤めている \\
\hline & Taishikan & $N i$ & Tsutometeiru \\
\hline & Kedutaan & $\mathrm{TB}$ & sedang bekerja \\
\hline & Bekerja di & 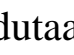 & \\
\hline
\end{tabular}

\section{(30/4/NGC I)}

Pada data (12) verba yang dimunculkan adalah tomaru yang artinya menginap. Dari verba ini dapat disimpulkan bahwa nomina yang mengikutiya pasti nomina yang berhubungan dengan tempat, dan partikel yang mengikutinya pasti menunjukkan perannya sebagai tempat sesuatu berada. Hal ini dibuktikan dengan munculnya nomina hoteru (hotel). Hotel adalah nomina yang menunjukkan tempat. Pada bahasa Jepang, partikel yang mengikuti keberadaan sesuatu adalah partikel ni. Hal ini sesuai dengan Otsuka yang menyatakan bahwa salah satu peran dari partikel $n i$ adalah perannya yang menunjukkan tempat sesuatu berada.

Sama halnya dengan dengan data (12), pada data (13) menunjukkan peran tempat berada yang ditunjukkan dengan nomina taishikan 'kedutaan' http://journal.unesa.ac.id/index.php/paramasastra |132 
menunjukkan tempat keberadaan dan partikel yang menempel pada nomina adalah partikel ni. Kedua data ini termasuk kedalam kolokasi terbatas.

\section{b. Tempat tujuan（目的地 - 到着点）}

Peran tempat partikel $n i$ adalah sebagai penanda tempat tujuan. Berikut contoh datanya:

$\begin{array}{lll}\text { (14) バスに } & \text { に } & \text { 乗ります } \\ \text { Basu } & N i & \text { norimasu } \\ \text { Bus } & \mathrm{TTj} & \text { menaiki } \\ \text { Menaiki bus } & \end{array}$

\section{$(130 / 16 / M N S ~ I)$}

Pada data (14) nomina basu 'bus' merupakan kata benda yang dapat merujuk sebagai sebagai tempat. Verba pada kalimat ini adalah notte yang berarti 'menaiki'. Kalimat pada data ini menunjukkan adanya tempat yang dituju untuk dinaiki. Partikel yang mengikuti nomina ini adalah partikel $n i$, jadi, partikel ini menunjukkan perannya sebagai penanda tempat tujuan yang melekat pada benda aatau tempat. Data ini termasuk ke dalam kolokasi terbatas.

\section{c. Tempat Keluarnya}

Peran terakhir pada partikel $n i$ dalam konstruksi Nomina $+n i+$ verba adalah sebagai penanda tempat keluar. Berikut contoh datanya:

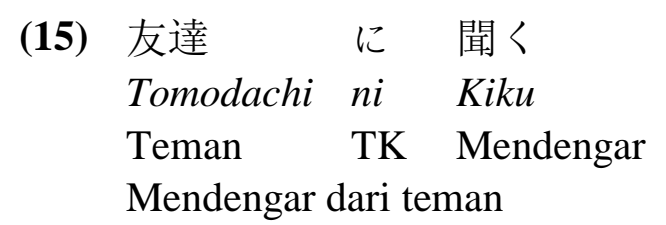

(66/8/NGC I)

Data (15) verba kiku merupakan verba yang berarti 'mendengar'. Nomina yang bervalensi dengan verba ini adalah tomodachi 'teman'. Pada data ini hal yang diketahui oleh subjek berasal dari teman. Jadi, teman dalam data ini merupakan tempat keluarnya informasi yang diperoleh subjek. Partikel $n i$ yang 
melekat pada nomina ini menunjukkan tempat keluarnya informa si, dan pada data ini, perannya dalam bahasa Indonesia dapat diartikan dengan 'dari'.

\subsection{Waktu（時間）}

Partikel $n i$ sebagai penanda kasus yang keempat, berperan sebagai penanda waktu. Berikut contoh datanya:
(16) 約束の時間
に間に合わないかもしれません
Yakusoku no jikan ni ma ni awanai kamoshiremasen
Janji JD waktu W mungkin tidak bisa tepat waktu
Mungkin tidak bisa tepat waktu (dalam) janji

(52/32/MNS II)

Pada data (16) frasa yakusoku no jikan 'waktu janji' berfungsi sebagaai subjek dan partikel $n i$ yang mengikuti frasa ini berperan sebagai penanda waktu. Frase ma ni awanai kamoshiremasen menerangkan adanya indikasi bahwa penutur tidak dapat datang tepat waktu. Frasa $m a n i$ au adalah frasa yang menunjukkan ketidaksesuaian atau ketidakcocokan terhadap waktu dan ukuran (KBBJI). Ma ni au termasuk ke dalam kolokasi terbatas.

\subsection{Arah（方向）}

Peran keenam pada partikel $n i$ dalam konstruksi Nomina $+n i+$ verba adalah sebagai penanda arah kegiatan. Berikut contoh datanya:

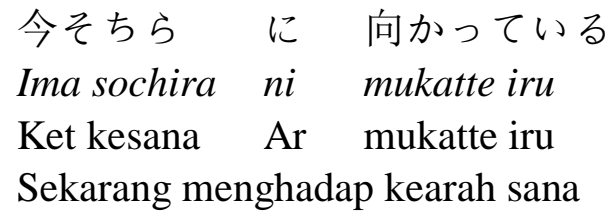

(171/46/MNS II)

Partikel ni pada data (17) melekat pada nomina sochira yang menjelaskan arah atau tempat dan merujuk pada kegiatan menghadap yang ditandai dengan verba mukatte iru. Hal ini menunjukkan bahwa partikel $n i$ yang menempel pada nomina ini merupakan partikel penanda arah kegiatan.

\subsection{Hasil / Akibat Perubahan（変化の結果）}


Peran berikutnya pada partikel $n i$ dalam konstruksi Nomina $+n i+$ verba adalah sebagai penanda hasil akibat perubahan. Berikut contoh datanya:

(18) 日本人と友達 Nihonjin to tomodachi になりましょう Orang Jepang JD teman ni narimashou Mari berteman derngan orang Jepang

Pada data (18) terjadi perubahan yanng diakibatkan sesuatu pada nomina. objek yang dituju oleh verba adalah nihonjin 'orang Jepang'. Tujuan dari kalimat nihonjin to tomodachi ni narimashou adalah subjek ingin menjadikan orang Jepang sebagai teman. Hal ini mengakibatkan terjadinya suatu hubungan dengan objek dan hasilnya adalah hubungan pertemanan. Pada peran partikel $n i$ yang menandakan akibat pengaruh biasa ditandai dengan verba narimasu. Kolokasi ini termasuk dalam kolokasi terbatas.

\subsection{Pemberi Pengaruh（受身分の影響の）}

Partikel $n i$ sebagai salah satu partikel penanda kasus pada peran berikutnya adalah sebagai penanda pemberi pengaruh. Berikut datanya:

(19) $\begin{array}{lll}\text { レポート } & \text { に } & \text { 追われる } \\ \text { Repooto } & \text { ni } & \text { Owareru } \\ \text { Laporan } & P b P & \text { Dikejar } \\ \text { Dikejar laporan (deadline) }\end{array}$

(90/10/NGC I)

Kalimat Repooto ni owareru pada data (19) berkonstruksi Nomina $+n i$ +Verba. Pada data ini, partikel ni melekat pada nomina repooto yang artinya laporan, menunjukkan bahwa nomina repooto bervalensi pada verba owareru. Repooto merupakan pemberi pengaruh pada verba owareru. Nomina ini berperan sebagai sesuatu yang memberi pengaruh agar hal tersebut harus dikerjakan oleh subjek, karena kemungkinan laporan harus segera diserahkan. Hal ini 
memunculkan tindakan agar sesuatu segera diselesaikan dan dengan segera pekerjaan tersebut harus tuntas dan dikumpulkan. Kolokasi ini termasuk dalam kolokasi terbatas.

\subsection{Penerima pengaruh}

$\begin{array}{lll}\text { (20) クララサンさんは私 } & \text { に } & \begin{array}{l}\text { 歌舞伎について質問しました } \\ \text { Kabuki ni tsuite shitsumon }\end{array} \\ \text { Kurara san wa watashi } & n i & \begin{array}{l}\text { shimashita } \\ \text { Shabuki tentang bertanya telah }\end{array} \\ \text { Clara JD saya } & \text { PnP } & \text { melakukan } \\ \text { Clara bertanya tentang Kabuki kepada Saya }\end{array}$

(97/37/MNS II)

Pada data (20) watashi berperan sebagai penerima tindakan oleh Kurarasan. Tindakan atau pengaruh yang dilakukan adalah kegiatan bertanya dalam hal ini menanyakan tentang Kabuki. Sebagai penerima pengaruh dari kegiatan bertanya tersebut, akibat yang ditimbulkan adalah watashi harus menjawab pertanyaan dari subjek atau pemberi pengaruh. Kolokasinya termasuk dalam kolokasi terbatas.

\section{Konstruksi Nomina (ga) Verba}

Konstruksi yang ketiga adalah konstruksi nomina (ga) verba. Pada pola konstruksi ini, Peran partikel ga sebagai penanda pasien merupakan satu-satunya peran yang ditemukan pada data kolokasi yang telah dikumpulkan. Berikut contoh datanya:

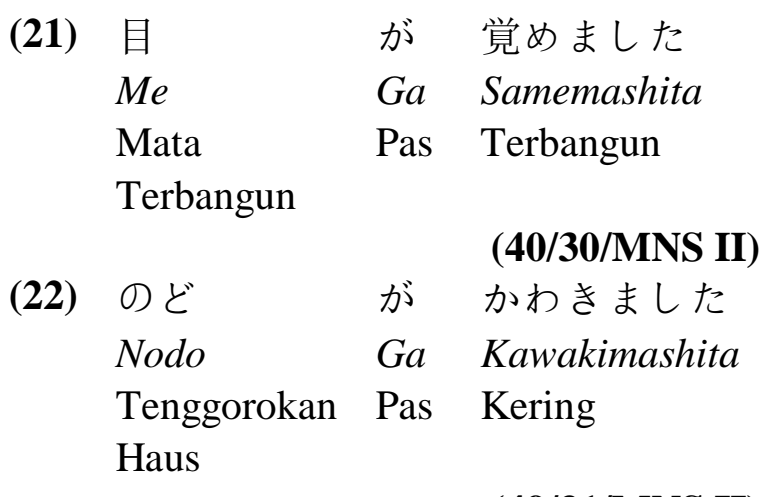


Pada data (21) dan (22) nomina me 'mata' dan nodo 'tenggorokan' merupakan nomina yang mengalami tindakan dan pengaruh oleh verbanya. Pada data (21), verba samemashita 'telah terbangun' memberikan pengaruh atau dampak kepada 'mata' agar terbuka dan akibatnya, subjek menjadi terbangun dari tidur. Begitu pula dengan data (22), akibat kering yang melanda pada tenggorokan, hasilnya adalah rasa haus. Hal ini mengindikasikan bahwa nomina yang ditempeli oleh partikel ga pada kedua data di atas mendapat pengaruh atau dampak dari kegiatan verba. oleh karenanya nomina ini disebut dengan pasien atau penerima pengaruh. Kedua data ini termasuk kolokasi idiom.

\section{Konstruksi Nomina (de) Verba}

Konstruksi yang keempat adalah konstruksi nomina (de) verba. Pada pola konstruksi ini, data yang didapat sejumlah 22 data. Berikut adalah tabel temuan data peran partikel $d e$ :

\subsection{Tempat kegiatan（動作の場所）}

Peran de pada konstruksi Nomina $+d e+$ Verba yang pertama adalah sebagai penanda tempat kegiatan. Berikut contoh datanya:
(23) あの花屋のまえ
で＼cjkstart止めてください
Ano hanaya no mae
De tomete kudasai
Depan toko bunga
TK tolong berhenti
Tolong berhenti di depan toko bunga
(24) レストラン
で働きます
Resutoran
De Hatarakimasu
Restoran
TK Bekerja
Bekerja di restoran

\section{(49/31/MNS II)}

Pada data (23) dan (24) nomina hanaya 'toko bunga' dan resutoran 'restoran' merupakan kata tunjuk tempat digunakan untuk menunjukkan tempat 
kegiatan dari verba berlangsung. Kegiatan yang pertama adalah berhenti dan yang kedua adalah bekerja. Kata hatarakimasu, menunjukkan adanya kegiatan yang dilakukan selama pekerjaan berlangsung. Kegiatan ini membutuhkan aktifitas gerak, berbeda halnya dengan kata tsutomeru yang sama-sama mempunyai arti bekerja. Kalau dalam tsutomeru, kegiatan yang berlangsung tidak membutuhkan aktifitas pergerakan dari subjek.

Partikel de pada kedua data di atas melekat pada nomina yang menunjukkan tempat kegiatan, hal ini berarti partikel de merupakan partikel yang berperan sebagai penanda tempat kegiatan. Dalam bahasa Indonesia, partikel ini biasa diartikan 'di'. Kedua data tersebut termasuk dalam kolokasi terbatas.

\subsection{Alat手段 · 道具}

Peran partikel de yang kedua adalah sebagai penanda alat yang digunakan. Berikut contoh datanya:

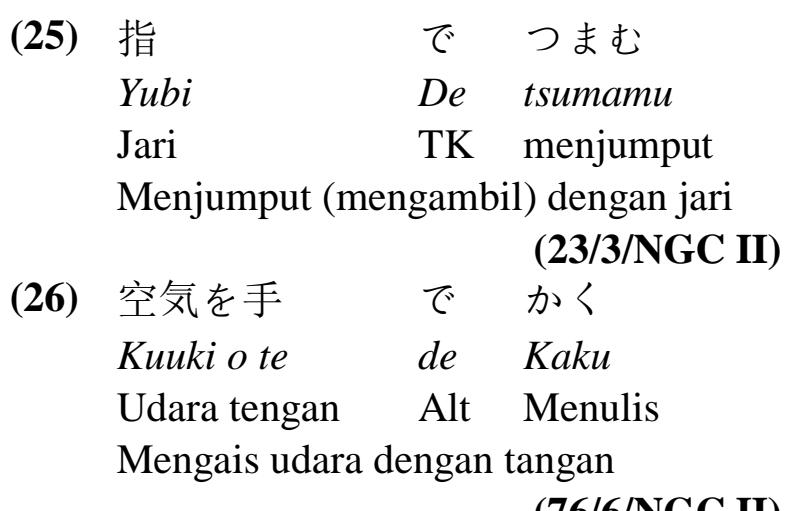

Pada data (25) nomina yuubi 'jari' dan te 'te' (26) merupakan bagian tubuh yang dapat difungsikan sebagai alat untuk melakukan suatu perbuatan apabila verba yang mengikutinya adalah verba yang dapat memunculkan aktifitas yang membutuhkan alat dan partikel yang mengikuti nominanya adalah partikel de.

Hal inilah yang mendasari peran partikel de sebagai penanda alat yang digunakan. Dalam bahasa Indonesia, peran partikel ini dapat diterjemahan dengan http://journal.unesa.ac.id/index.php/paramasastra |138 
'dengan'. Jenis kolokasi pada data (25) termasuk kolokasi terbatas, dan (26) adalah kolokasi kolokasi idiom.

\subsection{Penyebab/ Alasan原因 - 理由}

Peran partikel de yang ketiga adalah sebagai penanda alasan. Pada penanda sebab/alasan ini hanya diperoleh satu data saja, yakni:
(34) 病気で診てもらったほうがいいですよ
Byouki De Mite moratta houga ii desu yo
Sakit Als sebaiknya diperiksakan
Karena sakit, sebaiknya diperiksakan

(53/32/MNS II)

Pada data (34) kalimat byouki de moratta houga ii desu yo merupakan sebuah saran agar lawan bicara (yang tidak disebutkan) mengambil cuti. Nomina byouki 'sakit' nomina yang menjadi alasan, agar cuti atau waktu istirahat diambil. Partikel de yang melekat pada nomina ini sebagai penanda alasan/sebab pengambilan suatu keputusan. Pada bahasa Indonesia, partikel penanda alas an ini biasa diartikan dengan 'karena'. Kolokasi ini termasuk ke dalam kolokasi bebas.

\section{SIMPULAN}

Simpulan dari penelitian ini adalah sebagai berikut.

1. Berdasar dari hasil penelitian, terdapat 507 data tuturan yang mengandung kolokasi bahasa Jepang. Pola kontruksi modifikasi dari nomina + verba dan perannya dalam kalimat bahasa Jepang, ditemukan:

(a) Nomina $+w o+$ Verba dengan 5 peran semantik,

(b) Nomina $+n i+$ Verba dengan 11 peran semantik,

(c) Nomina $+g a+$ Verba dengan 1 peran semantik,

(d) Nomina $+d e+$ Verba dengan 4 peran semantik, 
2. Jenis kolokasi yang ditemukan pada penelitian ini adalah: terbatas, terikat dan idiom.

3. Penggunaan pola kontruksi yang paling banyak adalah Nomina $+o+$ Verba. Hal ini dapat menjadi dasar agar pola konstruksi ini menjadi pola kontruksi yang pertama dikenalkan kepada pembelajar bahasa Jepang.

\section{Saran}

Penelitian yang dilakukan oleh peneliti ini masih terbatas pada kontruksi "Nomina + Verba" serta peran dan jenis kolokasi bahasa Jepang pada Minna no Nihongo I, II dan Nihongo Chuukyuu I, II. Penelitian kolokasi dengan kontruksi lain masih dapat dilakukan, misalkan dalam bidang linguistik mengenai kolokasi dengan kontruksi "Adjektiva + Verba" beserta peran semantiknya dan lain sebagainya. Sumber data bisa melalui buku ataupun google, kamus dan lain sebagainya.

Pada bidang pendidikan, bisa meneliti mengenai pengaruh hubungan kemampuan penguasaan kolokasi terhadap kemampuan menulis siswa. Sumber datanya bisa melalui esai siswa dan lain sebagainya. Hasil dari penelitian kolokasi dapat dijadikan bahan ajar, baik itu berupa flash card, kamus kolokasi dan lain sebagainya. 


\section{DAFTAR PUSTAKA}

Gatari, Adelia Febry. 2011. Kolokasi. Universitas Islam Negeri Syarif Hidayatullah.(http://repository.uinjkt.ac.id/dspace/bitstream/123456789/291 17/1/SKRIPSI\%20ADELIA\%20FEBRY\%20GATARI.pdf) diunduh pada 20 Februari 2017

Ikuo, Kawasse, Itou Yoshiteru, Koide Keiichi, dan Saita Izumi. 1996. Nihongo Chuukyuu I. Tokyo: The Japan Foundation

Ikuo, Kawase dan Saita Izumi. 1996. Nihongo Chuukyuu II. Tokyo: The Japan Foundation

Lee, Bunpei. 2016. Chuugokujin Nihongo Gakushuusha no Tame no Korokeeshon Gakushuu no Shidouhou ni Kansuru Kisotekikenkyuu -Sakubun deeta $n$ Kizuku (Meishi+wo+doushi) no Korokeeshon no Chuushin ni-. (Disertasi tidak dipublikasikan). Universitas Nagoya.

Ogawa, Iwao. 1998. Minna no Nihongo Shokyuu I. Surabaya: 3A Corporation

Roni. 2013. Peran-peran Pada Konstituen Tidak Wajib Hadir Non-Nomina Beserta Perwujudannya. (Artikel elektronik). Jurnal Asa:Jurnal Ilmiah Prodi Pendidikan Bahasa Jepang Seputar Bahasa, Sastra dan Pengajarannya (https://tentangroni.files.wordpress.com/2014/01/jurnalnihongo-2013-10-jenis-jenis-peran-pada-nomina.pdf) diunduh pada $20 \mathrm{Juli}$ 2018

Roni. 2014. Verba Sebagai Pusat Kalimat dalam Bahasa Jepang: Konsentrasi pada Makna Sintaksis Nomina Tidak Wajib Hadir. (Artikel elektronik) Jurnal Aktual: Jurnal LPPM Unesa. Vol. 1, No. 02, Juni 2014. ISSN 2339-2894. (https://tentangroni.files.wordpress.com/2009/04/artikel-jurnal-aktual.pdf) diunduh pada 20 Juli 2018

Sudjianto, dan Ahmad Dahidi. 2004. Pengantar Linguistik Bahasa Jepang. Jakarta: Kesaint Blanc Publishing.

Sutedi, Dedi. 2008. Dasar-dasar Linguistik Bahasa Jepang (Edisi Ketiga). Bandung: Humaniora

Yone, Tanaka, dan kawan-kawan. 2002. Minna no Nihongo II. Surabaya: 3A Corporation 